\title{
КЛЮЧЕВЫЕ КОМПЕТЕНЦИИ ЭКОНОМИЧЕСКОГО РАЗВИТИЯ РЕГИОНОВ РОССИИ, НЕБЛАГОПРИЯТНЫХ ДЛЯ ВЕДЕНИЯ СЕЛЬСКОХОЗЯЙСТВЕННОГО ПРОИЗВОДСТВА*
}

\author{
(c) 2019 Васильченко Марианна Яковлевна \\ кандидат экономических наук, старший научный сотрудник \\ Институт аграрных проблем Российской академии наук, Россия, Саратов \\ E-mail: mari.vasil4enko@yandex.ru \\ (c) 2019 Трифонова Елена Николаевна \\ кандидат экономических наук, старший научный сотрудник \\ Институт аграрных проблем Российской академии наук, Россия, Саратов \\ E-mail: trif-elena@yandex.ru
}

В статье представлен анализ экономической специализации российских регионов, отраженной в Стратегии пространственного развития Российской Федерации на период до 2025 года. Дано методическое обоснование ключевых компетенций экономического развития регионов, неблагоприятных для ведения сельскохозяйственного производства с использованием индикаторов производственного потенциала животноводства и перерабатывающих отраслей.

Ключевые слова: ключевые компетенции; регионы, неблагоприятные для ведения сельского хозяйства; животноводство; пищевая промышленность

В современных условиях одной из наиболее актуальных проблем является обоснование стратегии развития агропромышленного комплекса и сельских территорий. В предыдущих исследованиях была осуществлена кластеризация неблагоприятных регионов Российской Федерации, проведен сравнительный анализ социально-экономических показателей по выделенным кластерам (монокластерам) и ближайшим благоприятным регионам; затронуты проблемы обоснования стратегии развития агропромышленного комплекса и сельских территорий [1].

Цель настоящего исследования состоит в обосновании ключевых компетенций экономического развития регионов, неблагоприятных для ведения сельскохозяйственного производства.

Методика выделения ключевых компетенций основывается на использовании ряда индикаторов производственного потенциала сельского хозяйства, позволяющих определить стратегически важные направления для развития сельских территорий с учетом сложившейся и перспективной экономической специализации, состояния ресурсного потенциала, институциональной структуры, а также возможностей государственной поддержки товаропроизводителей.
Результаты. Ключевые компетенции рассматриваются как наиболее важные области деятельности, являющиеся основой для развития и расширения производства. Ключевые компетенции направлены на реализацию целей, отражающих различные макроэкономические установки развития регионов, неблагоприятных для ведения сельскохозяйственного производства (импортозамещение, расширение экспорта, обеспечение занятости на селе и т.д). В процессе анализа использовались материалы Стратегии пространственного развития, определившей перспективную экономическую специализацию каждого региона РФ [2]. Следует отметить, что предложенная специализация представлена довольно укрупнено, что не позволяет выделить ключевые направления развития агропромышленного комплекса неблагоприятных регионов, тем более, что в некоторых случаях неперспективная специализация определена в качестве одного из необходимых условий функционирования региона. Для выявления ключевых компетенций предложены методические подходы, основанные на использовании индикаторов производственного потенциала отраслей АПК неблагоприятных регионов РФ (таблица 1).

\footnotetext{
* Работа выполнена при финансовой поддержке Российского фонда фундаментальных исследований, проект 18-010-00433 а «Обоснование стратегии развития агропродовольственных систем в регионах России, неблагоприятных для ведения сельского хозяйства, с использованием подходов дифференцированного управления».
} 


\begin{tabular}{|c|c|c|c|c|c|c|c|c|c|c|c|c|c|}
\hline \multicolumn{3}{|c|}{ 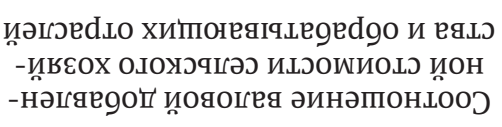 } & $\stackrel{\stackrel{m}{\sim}}{\sim}$ & $\stackrel{\stackrel{N}{-}}{\rightarrow}$ & $\stackrel{\stackrel{n}{\rightarrow}}{\rightarrow}$ & $\stackrel{0}{\stackrel{\infty}{\rightarrow}}$ & $\begin{array}{l}\infty \\
\stackrel{\infty}{-}\end{array}$ & $\underset{\tilde{i}}{\tilde{i}}$ & $\stackrel{a}{-}$ & $\vec{ت}$ & 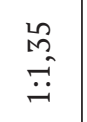 & $\begin{array}{l}\stackrel{n}{n} \\
\stackrel{i}{ت} \\
-1\end{array}$ & $\overrightarrow{\vec{r}}$ \\
\hline \multirow{3}{*}{ 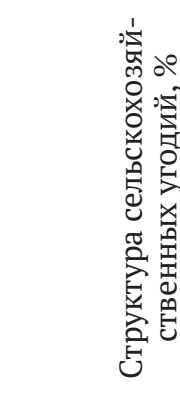 } & \multirow{3}{*}{ 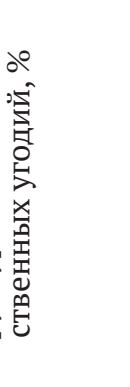 } & 喼 & $\begin{array}{l}n \\
\sigma^{2}\end{array}$ & $\tilde{O}_{0}^{-}$ & $\begin{array}{l}\infty \\
\infty^{-}\end{array}$ & 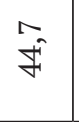 & $\stackrel{\circ}{i}$ & $\stackrel{2}{\approx}$ & $\stackrel{0}{=}$ & $\begin{array}{l}\text { m } \\
\text { î }\end{array}$ & $\begin{array}{l}\infty \\
\infty \\
\infty\end{array}$ & $\hat{\sigma}$ & $\overrightarrow{\mathrm{A}}$ \\
\hline & & 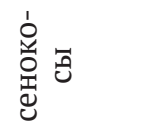 & $\begin{array}{l}0 \\
\ddot{N}\end{array}$ & î & $\stackrel{\infty}{\sharp}$ & $\stackrel{0}{\sigma_{0}^{-1}}$ & $\stackrel{+}{\text { in }}$ & $\overrightarrow{\theta_{0}^{0}}$ & $\stackrel{\sharp}{=}$ & $\begin{array}{c}m \\
\tilde{n}\end{array}$ & $\stackrel{H}{M}$ & $\begin{array}{l}n= \\
\text { in } \\
\text { in }\end{array}$ & $\vec{a}$ \\
\hline & & 畐 & $\begin{array}{l}\infty \\
\text { in } \\
\text { in }\end{array}$ & $\tilde{\sigma}^{m}$ & $\stackrel{+}{\sigma}$ & 命 & $\begin{array}{l}\text { M } \\
\text { q }\end{array}$ & $\stackrel{m}{\sim}$ & $\stackrel{\sim}{*}$ & $\stackrel{M}{M}$ & 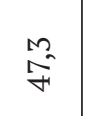 & $\begin{array}{l}\infty \\
\text { in } \\
m\end{array}$ & $\vec{a}$ \\
\hline \multirow{5}{*}{ 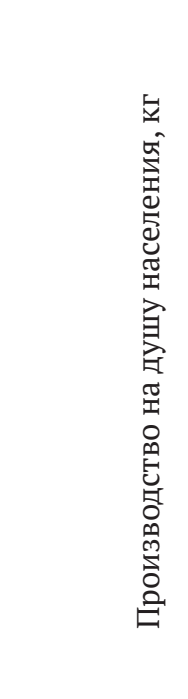 } & \multirow{5}{*}{ 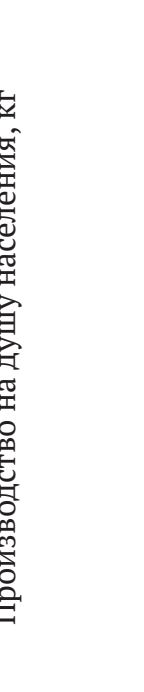 } & 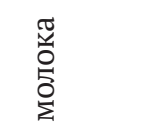 & 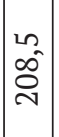 & $\vec{a}$ & $\stackrel{\widehat{N}}{\stackrel{\sim}{N}}$ & $\stackrel{m}{\Omega}$ & $\stackrel{0}{\infty}$ & $\begin{array}{l}\text { Oे } \\
\text { ț } \\
\text { N }\end{array}$ & $\begin{array}{l}\stackrel{m}{a} \\
\stackrel{a}{\sigma}\end{array}$ & $\underset{\sharp}{\tilde{t}}$ & $\begin{array}{l}m \\
\stackrel{M}{n}\end{array}$ & $\hat{\tilde{D}}$ & 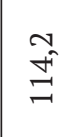 \\
\hline & & 惡奇 & $\begin{array}{l}\hat{\omega} \\
\hat{m}\end{array}$ & $\begin{array}{l}0 \\
\text { tే }\end{array}$ & $\stackrel{m}{\stackrel{m}{*}}$ & $\begin{array}{l}0 \\
\infty\end{array}$ & $\begin{array}{l}0 \\
\stackrel{2}{\sigma}\end{array}$ & $\overrightarrow{\mathrm{I}}$ & $\begin{array}{l}0 \\
\text { a } \\
=\end{array}$ & $\approx$ & $\stackrel{0}{\stackrel{0}{N}}$ & $\overrightarrow{+}$ & $\hat{\sigma}$ \\
\hline & & 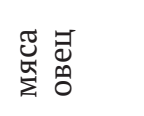 & $\stackrel{n}{-}$ & $\begin{array}{l}n \\
0 \\
0\end{array}$ & $\tilde{o}$ & $\overrightarrow{0}$ & 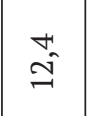 & $\stackrel{\circ}{\circ}$ & $\stackrel{m}{0}$ & 0 & $\stackrel{n}{\rightarrow}$ & $\underset{\sim}{0}$ & $\hat{0}$ \\
\hline & & 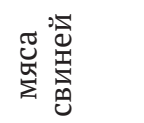 & $\mid \begin{array}{l}\text { in } \\
\text { so } \\
n\end{array}$ & $\stackrel{\sigma}{\stackrel{\leftrightarrow}{N}}$ & $\stackrel{\forall}{\infty}$ & $\hat{n}$ & $\stackrel{\circ}{\Rightarrow}$ & $\stackrel{M}{=}$ & $\vec{b}^{+H}$ & $\stackrel{n}{n}$ & $\stackrel{\vec{\lambda}}{\sigma}$ & $\stackrel{+}{=}$ & $\stackrel{m}{a}$ \\
\hline & & 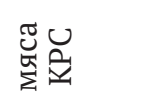 & $\stackrel{0}{=}$ & $\vec{i}$ & $\vec{N}$ & $\stackrel{+}{i}$ & $\stackrel{\infty}{\stackrel{\infty}{N}}$ & $\stackrel{\sim}{\sigma}$ & Mo & $\hat{0}$ & ㅇ. & $\overrightarrow{\Omega^{-}}$ & $\vec{a}$ \\
\hline \multirow{5}{*}{ 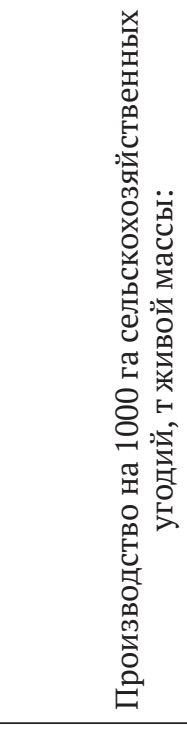 } & & $\begin{array}{l}\pi \\
\tilde{0} \\
\vdots \\
\vdots\end{array}$ & $\begin{array}{c}\infty \\
\stackrel{+}{n} \\
\sim\end{array}$ & 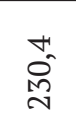 & \begin{tabular}{l} 
స̂. \\
\multirow{\delta}{*}{}
\end{tabular} & $\stackrel{\cong}{\cong}$ & $\stackrel{\vec{F}}{\vec{F}}$ & $\begin{array}{l}M \\
\tilde{N} \\
\tilde{N}\end{array}$ & के & 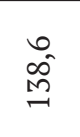 & $\begin{array}{l}0 \\
\stackrel{0}{0} \\
0\end{array}$ & $\overrightarrow{8}$ & $\stackrel{\sim}{\stackrel{0}{N}}$ \\
\hline & & 冚寄 & $\hat{\mathrm{m}}$ & $\begin{array}{l}0 \\
\text { ti }\end{array}$ & 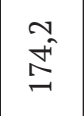 & $\stackrel{H}{N}$ & $0_{0}^{0}$ & ڤn & $\stackrel{+H}{\infty}$ & $\hat{\sim}$ & 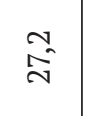 & 2 & $\stackrel{\infty}{i}$ \\
\hline & & 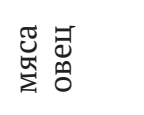 & 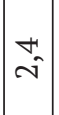 & $\hat{\sigma}$ & $\tilde{0}$ & $\begin{array}{l}\text { Ln } \\
0\end{array}$ & $\overrightarrow{0}$ & $\stackrel{\sim}{\infty}$ & $\stackrel{\infty}{0}$ & $\ddot{O}$ & in & $\underset{\sim}{0}$ & $\stackrel{\infty}{-}$ \\
\hline & & 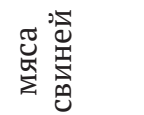 & $\stackrel{M}{\stackrel{M}{N}}$ & $\stackrel{\stackrel{H}{+}}{\stackrel{H}{N}}$ & 今ે & 으 & $\stackrel{n}{n}$ & $\stackrel{\infty}{\rightarrow}$ & $\tilde{\sigma}$ & $\stackrel{H}{\stackrel{H}{q}}$ & $\stackrel{M}{\stackrel{N}{N}}$ & $\cong$ & $\vec{\infty}$ \\
\hline & & $\begin{array}{l}\tilde{J} U \\
\sum_{\Sigma}\end{array}$ & $\overrightarrow{\nexists t}$ & 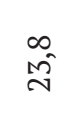 & ब्ञ & $\begin{array}{l}n \\
0 \\
0\end{array}$ & $\begin{array}{l}0 \\
a\end{array}$ & $\begin{array}{c}\infty \\
\stackrel{1}{\infty}\end{array}$ & $\stackrel{=}{=}$ & $\stackrel{0}{=}$ & $\stackrel{4}{\sim}$ & $\stackrel{\infty}{=}$ & $\hat{0}$ \\
\hline \multicolumn{3}{|c|}{ 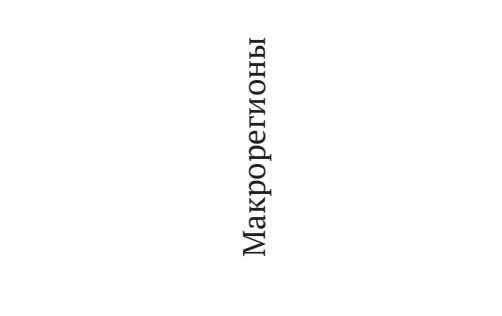 } & $\theta$ & 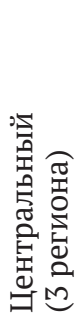 & 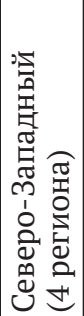 & 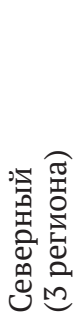 & 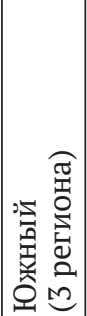 & 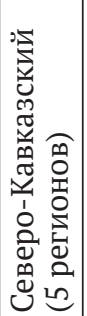 & 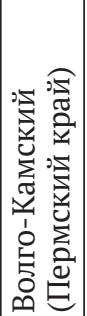 & 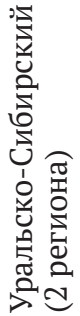 & 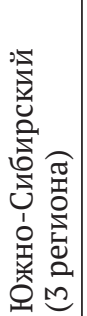 & 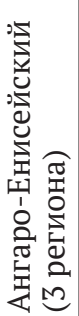 & 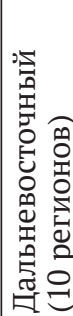 \\
\hline
\end{tabular}


Определение вклада регионов в продовольственное обеспечение показывает индекс локализации производства в расчете на единицу земельной площади. По уровню локализации мяса крупного рогатого скота лидируют СевероЗападный и Северо-Кавказский макрорегионы; мяса свиней - Северо-Западный и УралоСибирский макрорегионы; мяса овец - Южный и Северо-Кавказский макрорегионы; молока Северо-Кавказский и Центральный макрорегионы. В то же время производство мяса свиней в расчете на душу населения ниже общероссийского показателя во всех макрорегионах, молока - в большинстве макрорегионов (за исключением Центрального и Северо-Западного). Практически во всех макрорегионах (за исключением Южного, Северо-Кавказского и Дальневосточного) приоритетное значение играют обрабатывающие отрасли, хотя их состав имеет существенные различия.

Например, в Мурманской области (СевероЗападный макрорегион) ведущими отраслями являются: горнодобывающая промышленность, металлургия и электроэнергетика, мукомольная, хлебопекарная, молочная, мясная отрасли. В Сахалинской области ведущую роль играет ры- бохозяйственный комплекс [3]. Для выявления региональных различий были рассчитаны отдельные показатели переработки сельскохозяйственной продукции (табл. 2).

Наиболее развита переработка мясо-молочной продукции в Центральном макрорегионе, причем среднероссийский уровень превышен по всем вышеперечисленным продуктам. Особо следует выделить Брянскую область, выделяющуюся высоким уровнем как производства, так и переработки. В области достигнуто самообеспечение по сырам и сырной продукции, что объясняется экологически неблагоприятными условиями и необходимостью снижения радионуклидов в процессе переработки молочного сырья [4].

Основное отличие Северо-Кавказского и Дальневосточного макрорегионов состоит в высокой концентрации неблагоприятных регионов на их территории (в Северо-Кавказском -5 из 7 ; в Дальневосточном - 10 из 11). Значительная часть земельной площади Северо-Кавказского макрорегиона относится к горным и предгорным территориям с неудовлетворительным состоянием почв. Условия ведения сельскохозяйственного производства определяются пре-

Таблица 2. Показатели переработки сельскохозяйственной продукции в регионах, неблагоприятных для ведения сельского хозяйства (2017 г.)

\begin{tabular}{|l|c|c|c|c|}
\hline \multirow{2}{*}{ Макрорегионы } & \multicolumn{4}{|c|}{ Производство на душу населения, кг } \\
\cline { 2 - 5 } & $\begin{array}{c}\text { Мясо и субпро- } \\
\text { дукт (в убойной } \\
\text { массе) }\end{array}$ & Сливочное масло & Колбасы & $\begin{array}{c}\text { Сыры и сырные } \\
\text { продукты }\end{array}$ \\
\hline РФ & 4,4 & 1,8 & 15,3 & 50,9 \\
\hline $\begin{array}{l}\text { Центральный } \\
\text { (3 региона) }\end{array}$ & 15,1 & 3,7 & 50,1 & 82,1 \\
\hline $\begin{array}{l}\text { Северо-Западный } \\
\text { (4 региона) }\end{array}$ & 0,8 & 1,9 & 8,9 & 71,2 \\
\hline $\begin{array}{l}\text { Северный } \\
\text { (3 региона) }\end{array}$ & 0,1 & 1,2 & 9,1 & 12,1 \\
\hline $\begin{array}{l}\text { Южный } \\
\text { (3 региона) }\end{array}$ & 3,8 & 1,1 & 3,3 & 16,3 \\
\hline $\begin{array}{l}\text { Северо-Кавказский } \\
\text { (5 регионов) }\end{array}$ & 0,8 & 0,2 & 0,7 & 21,9 \\
\hline $\begin{array}{l}\text { Волго-Камский } \\
\text { (Пермский край) }\end{array}$ & 4,8 & 2,1 & 9,1 & 5,5 \\
\hline $\begin{array}{l}\text { Уральско-Сибирский } \\
\text { (2 региона) }\end{array}$ & 0 & 0 & 9,4 & 39,1 \\
\hline $\begin{array}{l}\text { Южно-Сибирский } \\
\text { (3 региона) }\end{array}$ & 0,3 & 1,2 & 8,7 & 1,3 \\
\hline $\begin{array}{l}\text { Ангаро-Енисейский } \\
\text { (3 региона) }\end{array}$ & 0,6 & 0,9 & 11,9 & 8,6 \\
\hline $\begin{array}{l}\text { Дальневосточный } \\
\text { (10 регионов) }\end{array}$ & 0,1 & 0,4 & & \\
\hline
\end{tabular}


обладанием мелкотоварного производства (например, производством мяса и молока занято до 95\% данной категории хозяйств. Необходимо отметить более низкую землеобеспеченность личных подсобных хозяйств населения и крестьянских хозяйств. Средняя площадь земельных участков, находящихся в личном владении и пользовании сельских предпринимателей составляет 9,4 га; разброс находится в интервале от 2,5 га в Карачаево-Черкесской Республике до 16 га в Республике Адыгея [5].

По производству мяса крупного рогатого скота и молока на душу населения макрорегион превышает среднероссийские показатели. Например, рассчитанный нами коэффициент региональной специализации по производству молока составил в Карачаево-Черкесской Республике 1,9 ; производству говядины и баранины 2,0 и 10,4 соответственно. Учитывая преобладание мелкотоварного производства, скотоводство и овцеводство будут и в дальнейшем определять вектор развития макрорегиона. Вместе с тем улучшение использования ресурсного потенциала малых и средних предприятий связано с организацией углубленной переработки животноводческой продукции, в том числе и на основе стратегической кооперации с соседними регионами. Согласно данным Центра изучения молочного рынка, в неблагоприятных регионах Северо-Кавказского макрорегиона (за исключением Карачаево-Черкесской Республики) наблюдается существенный дефицит мощностей по переработке молока. Возможно создание молочного кластера на основе ресурсов КабардиноБалкарской и Карачаево-Черкесской республик [5].

В неблагоприятных регионах приоритеты отводятся производству животноводческой продукции и кормовых культур. Несмотря на то, что в отдельных регионах Южно-Сибирского и Ангаро-Енисейского макрорегионов получило развитие производство зерновых культур, важнейшим ограничением является недостаточно развитая логистическая инфраструктура, в т.ч. и транспортная. Поэтому в этих регионах более предпочтительным является расширение собственной кормовой базы, в основном рапса и сои. Согласно данным официальной статистики, в 2017 г. доля Кемеровской и Томской областей (Южно-Сибирский макрорегион) в общероссий- ском объеме производства ярового рапса составила $8,2 \%$. По действующей программе «Производство и переработка рапса» в Иркутской области предполагается увеличить валовой сбор ярового рапса к 2021 г. по сравнению с 2015 г. в 32,7 раза [6], что будет также способствовать расширению объемов его переработки. Минсельхоз предлагает субсидировать развитие производства рапса и сои, причем субсидии будут выделяться тем регионам, которые выбрали приоритеты по соответствующим подотраслям АПК в рамках регионализации.

Природно-климатические условия Дальнего Востока существенно ограничивают развитие сельского хозяйства: около 20\% пашни переувлажнено или заболочено, в том числе в Магаданской области - свыше 50\%. Отличительная особенность макрорегиона - неравномерное развитие производства и переработки. В северной части преобладает сырьевая специализация, а южных (Хабаровский край) имеет место диверсификация экономики, в том числе и перерабатывающих производств. Однако отказ от ведения сельского хозяйства вследствие его убыточности уменьшает возможности развития сельских территорий. Так, в 2016 г. из 190 сельскохозяйственных предприятий Амурской области разведением крупного рогатого скота занимались только 42 предприятия [7].

Анализ показал, что при выборе ключевых компетенций вырисовываются следующие направления развития агропромышленного комплекса: расширение экспорта; импортозамещение; увеличение занятости населения как основа развития сельских территорий (таблица 3).

Для определения ключевых компетенций использовались предложенные интегральные индексы производства и переработки животноводческой продукции. Учитывая разнообразие условий производства животноводческой продукции по макрорегионам, можно выделить ориентированные на экспорт мяса свиней и птицы (Центральный и Северо-Западный); ориентированные на импортозамещение продукции животноводства (Северо-Кавказкий, Волго-Камскй, Южно-Сибирский и АнгароЕнисейский); обеспечение занятости населения как условие развития сельских территорий (Северный, Волго-Камский, Урало-Сибирский и Дальневосточный). 
Таблица 3. Ключевые компетенции экономического развития регионов России, неблагоприятных для ведения сельскохозяйственного производства

\begin{tabular}{|c|c|c|c|}
\hline Макрорегионы & $\begin{array}{c}\text { Интегральный } \\
\text { индекс произ- } \\
\text { водства живот- } \\
\text { новодческой } \\
\text { продукции }\end{array}$ & $\begin{array}{l}\text { Интегральный } \\
\text { индекс перера- } \\
\text { ботки живот- } \\
\text { новодческой } \\
\text { продукции }\end{array}$ & $\begin{array}{l}\text { Ключевые компетенции } \\
\text { экономического развития }\end{array}$ \\
\hline РФ & 1 & 1 & - \\
\hline $\begin{array}{l}\text { Центральный } \\
\text { (3 региона) }\end{array}$ & 1,1 & 2,47 & $\begin{array}{l}\text { Мясное скотоводство (Брянская, Владимирская } \\
\text { области), углубленная переработка молока и } \\
\text { мяса, экспорт мясо-молочных продуктов }\end{array}$ \\
\hline $\begin{array}{l}\text { Северо-Западный } \\
\text { (4 региона) }\end{array}$ & 0,53 & 0,66 & $\begin{array}{l}\text { Мясо-молочное скотоводство, углубленная пере- } \\
\text { работка молока и экспорт продуктов с высокой } \\
\text { добавленной стоимостью (Вологодская, Ленин- } \\
\text { градская области); рыболовство и рыбоводство } \\
\text { (Мурманская, Ленинградская). }\end{array}$ \\
\hline $\begin{array}{l}\text { Северный } \\
\text { (3 региона) }\end{array}$ & 0,17 & 0,54 & $\begin{array}{l}\text { Производство мяса крупного рогатого скота, } \\
\text { свиней, птицы и молока. Развитие углубленной } \\
\text { переработки молока и мяса. Целеполагающие } \\
\text { установки: развитие сельских территорий (Ре-- } \\
\text { спублика Коми и Ненецкий автономный округ); } \\
\text { импортозамещение (Архангельская область без } \\
\text { Ненецкого автономного округа) }\end{array}$ \\
\hline $\begin{array}{l}\text { Южный } \\
\text { (3 региона) }\end{array}$ & 1,33 & 0,42 & $\begin{array}{l}\text { Мясное скотоводство, овцеводство, переработ- } \\
\text { ка мяса (Республика Калмыкия); переработка } \\
\text { мяса и молока (Волгоградская область) с целью } \\
\text { импортозамещения }\end{array}$ \\
\hline $\begin{array}{l}\text { Северо-Кавказский } \\
\text { (5 регионов) }\end{array}$ & 1,3 & 0,38 & $\begin{array}{l}\text { Мясо-молочное скотоводство, овцеводство, } \\
\text { туризм, рекреационная деятельность, развитие } \\
\text { переработки молока и мяса с целью более пол- } \\
\text { ного использования сырьевых ресурсов (в том } \\
\text { числе на основе межрегиональной кооперации). } \\
\text { Целеполагающая установка: импортозамещение }\end{array}$ \\
\hline $\begin{array}{l}\text { Волго-Камский } \\
\text { (Пермский край) }\end{array}$ & 0,39 & 0,83 & $\begin{array}{l}\text { Углубленная переработка мясомолочной про- } \\
\text { дукции, туризм. Целеполагающая установка: } \\
\text { импортозамещение. }\end{array}$ \\
\hline $\begin{array}{l}\text { Уральско-Сибирский } \\
\text { (2 региона) }\end{array}$ & 0,01 & 0,01 & $\begin{array}{l}\text { Сырьевая направленность животноводства с } \\
\text { локальной переработкой. Целеполагающая уста- } \\
\text { новка: развитие сельских территорий }\end{array}$ \\
\hline $\begin{array}{l}\text { Южно-Сибирский } \\
\text { (3 региона) }\end{array}$ & 0,79 & 0,42 & $\begin{array}{l}\text { Мясное скотоводство (Республика Алтай), } \\
\text { производство свинины (Кемеровская и Томская } \\
\text { области), производство мяса птицы } \\
\text { (Томская область), производство кормовых куль- } \\
\text { тур (Кемеровская область), углубленная пере-- } \\
\text { работка животноводческой продукции, туризм. } \\
\text { Целеполагающая установка: импортозамещение }\end{array}$ \\
\hline $\begin{array}{l}\text { Ангаро-Енисейский } \\
\text { (3 региона) }\end{array}$ & 0,81 & 0,41 & $\begin{array}{l}\text { Мясное скотоводство (Республики Тыва и Ха- } \\
\text { касия), Алтай), производство свинины, молока, } \\
\text { мяса птицы, возделывание рапса (Иркутская } \\
\text { область), переработка животноводческой про- } \\
\text { дукции, туризм. Целеполагающая установка: } \\
\text { импортозамещение }\end{array}$ \\
\hline $\begin{array}{l}\text { Дальневосточный } \\
\text { (10 регионов) }\end{array}$ & 0,38 & 0,43 & $\begin{array}{l}\text { Мясное скотоводство (Республика Бурятия и } \\
\text { Забайкальский край), производство свинины, } \\
\text { молока, рыболовство и рыбоводство. Целепола- } \\
\text { гающая установка: развитие сельских террито- } \\
\text { рий; экспорт рыбы и продукции ее переработки, } \\
\text { туризм }\end{array}$ \\
\hline
\end{tabular}




\section{Библиографический список}

1. Андрющенко С.А., Васильченко М.Я., Шабанов В.Л. Оценка направлений развития агропродовольственных систем регионов России, признанных неблагоприятными для ведения сельского хозяйства // Международный сельскохозяйственный журнал. 2019. № 4 (370). С. 16-20.

2. Распоряжение Правительства РФ от 13.02.2019 N207-р «Об утверждении Стратегии пространственного развития Российской Федерации на период до 2025 года».-Режим доступа: www.consultant.ru.

3. Андрющенко С.А., Трифонова Е.Н. Основные тенденции и перспективы развития пищевой промышленности приполярных регионов России, неблагоприятных для ведения сельского хозяйства // Московский экономический журнал (QJE.SU), № 7/2019. -Режим доступа: http://qje.su/nauki-o-zemle/moskovskijekonomicheskij-zhurnal-7-2019-25.

4. Атаманова О.В. Индикаторы самообеспеченности Брянской области молочной продукцией: инструменты оценки, анализ и прогноз // Проблемы прогнозирования. 2013. № 6. С. 44-48.

5. Колесников Ю.С., Овчинников В.Н., Кетова Н.П. «Укорененная» экономика в структуре хозяйственного комплекса региона: ресурсы, экономические активы, воспроизводст-енный потенциал (опыт эмпирического исследования) // Проблемы прогнозирования, 2019, № 2. С. 141-151.

6. Программа «Производство и переработка рапса в Иркутской области на 2016-2021 годы».- Режим доступа: https://rosselhoscenter.com/regions/sibirian/irkutskaya-oblast/5975.

7. Дьяченко В. Трансформации аграрных поселений в Дальневосточном регионе // АПК: экономика, управление. 2019. № 5. С. 74-79. 